\title{
The Effect of the CAREY Program on the Students' Reading Attitude towards Reading English Materials
}

\author{
Marwan Yahya Al-Shawesh ${ }^{1} \&$ Supyan Hussin ${ }^{1}$ \\ ${ }^{1}$ Faculty of Social Sciences and Humanities, Universiti Kebangsaan Malaysia, Bangi, Selangor, Malaysia \\ Correspondence: Marwan Yahya Al-Shawesh, Faculty of Social Sciences and Humanities, Universiti \\ Kebangsaan Malaysia. Tel: 006-0107121018. E-mail: alshawesh85@gmail.com
}

Received: October 9, 2015 Accepted: November 15, 2015 Online Published: November 18, 2015

doi:10.5539/elt.v8n12p98 URL: http://dx.doi.org/10.5539/elt.v8n12p98

\begin{abstract}
Reading is one of language learning skills which has a great significance for the role it plays in the second language acquisition (SLA) process. The aim of this paper was to examine the extent to which the CAREY (Computer-Assisted Reading Yemen) program affects the Yemeni EFL students' reading attitude towards reading English materials. To achieve this objective, the data was collected from pre-and post-questionnaires of reading attitude. Additionally, the data was collected based on an interview and an observation. 20 students selected purposively from level one of an English proficiency course, Department of English, Faculty of Arts, Ibb University, Yemen in this study. All participants answered the pre- and post- reading questionnaires, and five of them were further interviewed. The study used both quantitative and qualitative analyses of the data including descriptive statistics of the responses from the questionnaires and thematic analysis of responses from the interviews. The results revealed that all participants showed their positive attitudes toward reading English materials especially after they joined the class of reading via CAREY program. In addition, it was found that CAREY program positively affected the participants' attitudes towards reading English materials.
\end{abstract}

Keywords: CAREY program, Yemen, EFL students' attitude of reading, web-based reading, computer- assisted reading

\section{Introduction}

Reading is one of language learning skills which has a great significance for the role it plays in the second language acquisition (SLA) process. Therefore, paying a great attention to its teaching and learning has to be the main objective of teachers and learners of any language. As far as English is concerned, reading has so much importance especially in the process of text comprehension. However, it has been defined by Widdowson (1979) as the procedure of acquiring linguistic information by copying. Grellet (1996: 8) illustrated that reading "constantly involves guessing, predicting, checking and asking oneself questions." Furthermore, reading skill seems to be very important because it is the most common skill learners are continuously going throughout the course in the learning process. In addition, Rahman (2007:11) stated that "reading is not just an act of going through the text, but it involves certain attitudes and reactions towards the text while reading the text. The author added that "reading is not a passive skill. It requires frequent practice and exercise" (Rahman 2007:10). Likewise, Nasr (2011) stated that reading skill is considered as the most important skill of the four skills especially in the countries where English is not the mother tongue or used as a foreign or a second language (FL/L2). In fact, reading is not and cannot be separated from other skills like speaking, listening, and writing. There is a strong interdisciplinary relationship among such skills. However, it is observed that Yemeni universities students read their texts, books and any other materials that get into their hands in the traditional way that does not qualify them well. Nasr (2011:25) stated that "the methods used for teaching reading in Yemen schools so far are inappropriate, and the teachers use the old method instead of using the appropriate technology and techniques of teaching reading". In this perspective, Iman (2008) and Balfakeh (2009) among other studies carried out in Yemen argued that Yemeni secondary school students and Sana'a University's students have problem in the process of texts' comprehension as they did not realize the importance of reading strategies in texts' comprehension. The reading skills need to be researched and investigated in most of the educational associations and the reasons behind the learners' negative result in this skill. The students just read the materials without paying attention to what they are reading, and they sometimes encounter a new word or a complex sentence 
structure that may prevent their understanding of the text. Unfortunately, most of the universities, schools and institutes in Yemen are teaching the English language in a conventional way, i.e., reading the printed text silently or aloud. This is emphasized by Nasr (2011:25) who pointed out that "Yemeni teachers in the primary schools are not properly trained in teaching English as a foreign language. They cannot make students learn reading process in a better manner. The teachers use the old method instead of using the appropriate technology and techniques of teaching reading".

Rajehy (2004:2) stated that "the way which reading courses are taught does not offer a kind of help for the students to further their advanced language reading skills to be developed through literature courses. In the EFL Yemen context, instructors of English are paying more attention to listening, speaking and writing while almost neglecting reading skill. In general, learners tend to depend on traditional materials (e.g. handouts) prescribed by university instructors for reading skill (David, 2004; Tanyeli, 2009; Biancarosa \& Griffiths, 2012; Muthanna \& Karaman, 2011; Al-Sohbani \& Muthanna, 2013). However, appropriate reading materials for these university students are unavailable online. There is a need to create specific reading package that will provide training to read, learning to read, and reading to learn for Ibb university students in Yemen. In line with this, the Internet is presented as a powerful tool for enhancing EFL learners' language learning including reading (Konishe, 2003; Balajthy, 2007; Simsek, 2008; Cheung \& Slavin, 2011; Al-Shawesh, 2012; Abanomey, 2013; Moqbel \& Rao, 2013; Han \& Wang, 2013) through authentic materials. Thus, reading becomes the most effective skill in this case, and the learners must be highly trained to get used to the techniques of reading especially through the Internet. This is also supported by Park and Kim (2011:2161) who stated that "participants considered videos and pictures important resources in online reading environments, and they regarded the resources as helpful for reading English text and studying English". Therefore, the study reported in this paper aimed to examine the extent to which the CAREY program affects the students' reading attitude towards reading English materials.

\section{Review of Previous Studies}

Integrating technology in teaching reading has attracted many researchers. For examples, Hong (1997) carried out a study to see the effectiveness of the multimedia computer-assisted reading in Chinese business comparing to the conventional paper-pen-dictionary reading method. The findings indicated that the use of multimedia computer-assisted reading is more effective in the efficiency of students' reading and reading comprehension than the conventional method. Next, Stakhnevich (2002) carried out a study to investigate the impact of the Web as an instructional medium in the process of second language comprehension during the independent reading. The findings showed that the medium of web has an impact on the process of reading comprehension. In addition to that, it was suggested that the teaching through web medium will achieve better in the process of comprehension than the traditional medium. In addition, Busch (2003) presented a study to show how computer technology can enable and motivate the students to read in a foreign language. The study revealed that the online materials and web-based application played a vital role in language learning through buying some more time and to convert certain in-class activities. The involvement of new online teaching materials is needed for language learning. Interactive contact with technology by the students and the teachers are important. Later, Tozcu and Coady (2004) carried out an experiment to find if students in the treatment group who used the Tutorial Computer-Assisted Language Learning were affected in acquiring large number of vocabulary, reading comprehension, and speed of words recognition comparing to those who do not use this program. The participants were 56 intermediate level students studying English for university academic preparation. They were assigned randomly to 28 students in the treatment group and 28 in the control group. The researcher used a survey introduced to the subjects. Pre-test and the post-test were given to the samples. The treatment group were provided with the computer-assisted program. The findings showed that despite the gain of both groups, the treatment group shows greater achievements in learning a larger number of words, in better reading comprehension and speed of word recognition. Moreover, LeLoup and Ponterio (2005) stated that the frequent reading is an effective way to develop and improve the process of reading comprehension. LeLoup and Ponterio (2005:3) pointed out that "the accessibility of a huge variety of authentic online reading material is a boon to all who wish to use and practice their language skills in the real world". They added that the "independent online reading is also an excellent way to encourage the motivated learner to become engaged in real interpretive communication by reading authentic texts for interesting content rather than solely for language practice" (LeLoup \& Ponterio 2005:3). Next, Tseng (2007) conducted a study to investigate how the EFL students read through the Internet network and to "compare reading skills between printed text and hypertext". The findings showed that the majority of the students preferred to read text-based paper. They preferred reading based paper while comprehending the reading skills more than reading by hypertext; this is happened due to the inappropriate designing of the program such as the font size, the background colour, download speed, and screen. The study of 
Tseng (2007) which highlighted the positive benefits of technology in teaching reading are supported by the study of Chem and Lin (2009) and Abanomey (2013). In Abanomey's (2013) study he investigated the impact of online format on the performance of Saudi-English as foreign language (EFL) learners and compared it with the traditional papers. The data was collected through reading comprehension test, which was carried out in two groups. The first group joined the digital reading presented by online passage, whereas second group joined to the conventional reading presented by printed passage. The findings showed that the reading based on the internet have an impact of the performance of the students in the process of reading comprehension whereas the traditional reading have less impact on the performance of the students. In terms of reading strategies, Chem and Lin (2009) conducted a study aimed to investigate EFL learners' reading strategies and the effect of strategy in the process of reading comprehension. Regarding the data collection, it was noticed that Chem and Lin (2009) designed a program namely "English reading online" to collect the data on readers' online strategies. The findings revealed that the supporting strategies have dominated in the process of comprehension whereas the global strategies achieved a better comprehension in the process of reading. The studies of Chem and Lin (2009) and Abanomey (2013) revealed that online reading is beneficial for the students to improve their reading performance. Tanyeli (2009) carried out a study to investigate if the students of the faculty of law in Eastern Mediterranean University (EMU) are learning well while reading by web. The findings depicted that the students of the Faculty of Law showed a successful learning while using the web-assisted learning and teaching. In this regard, it could be said that the inappropriate design might have a negative impact on the students and this is approved by Tseng (2010) who carried out a study to investigate how the online reading impacts the process of comprehension among ESL students. The findings revealed that the ESL students preferred the traditional reading than online reading for many reasons. These reasons were that the inappropriate design of the background colour of web pages and font size. "The major difficulties included eyestrain, inability to take notes or underline text, and skipping lines when reading hypertext on computer screens" (Tseng 2010:96). In addition, students found that reading through hypertext and hypermedia is more difficult than reading through printed texts. The role of the computer applications and modern technology must be engaged in the process of learning and teaching English language. The role of computer applications and modern technology will guide the learners for a better learning. In this regard, Alshawesh (2012) carried out a study to investigate the EFL Yemeni learner's attitudes and challenges towards using online chat rooms for learning English. The findings indicated that the majority of the respondents reported a positive attitude toward the English language learning. They emphasized that some of the technology applications such as chat room icons is a valuable and beneficial tool for enhancing English foreign language learners. Biancarosa and Griffiths (2012) stated that the development of modern technology nowadays gave the desire and hopes for many teachers, policy makers, administrators who believe in the great help of the modern technology. Last but not least, Chiu (2013) conducted a study to see the effectiveness of computer assisted instruction on learning and teaching particularly on learning vocabulary. The study revealed that computer-assisted instruction has positive effects towards learning L2 vocabulary. An interest of the application of technology is found by the learners in this study.

\section{Method}

\subsection{Research Question}

This study aimed to answer the following research question:

To what extent does the CAREY program affect the students' reading attitude towards reading English materials?

\subsection{Study Design}

The qualitative and quantitative methods were employed in this recent research in order to examine the extent to which the CAREY program affects the EFL Yemeni students' reading attitude towards reading English materials. Ashcroft and Palacio (1996) reported that, in the past, immense importance was placed for data to be collected through scientific means and to go through statistical analysis. In the quantitative method, the data were collected based on pre-test and post-test of reading attitude questionnaire plus three open ended questions. Willard and Harley (1986: 43) stated that "a questionnaire is designed to help you determine your most important emotional needs and evaluate your spouse's effectiveness in meeting those needs. In the qualitative method, the data were collected based on a semi-structured interview and observation checklists. Gay, Airasian, and Rubin (2000-1995 in Nadzrah 2005: 90) stated that "interviews are an effective way to understand, discover and explore individual attitudes, interests, feelings and concerns". In other words, the questionnaire and interview questions which were used in the present study were adapted from the study conducted by Mohaida (2006), who provided evidence of the reliability and validity of each measurement.

In this study, CAREY program was designed in five phases using ADDIE instructional model (Morrison 2010). 
The five phases are Analysis, Design, Development, Implementation, and Evaluation (ADDIE). It was designed and developed in order to provide the EFL Yemeni learners at Ibb University with the online reading materials. The online reading materials include reading lessons, reading texts, and reading activities. The reading lessons consist of tutorials on the concepts and skills on how to read. The reading materials comprises passages, newspapers, magazines, short and long stories, essays, articles, novels, dramas, and reports, whereas the reading activities presented include tasks, asking questions, pictures, animations, completing multiple choice questions, matching, fill in the blank, rearranging words, and doing crossword puzzles.

\subsection{Sample of Population}

A purposive sampling was employed in this research. The purposive sampling is defined by Maxwell (1998:87) as a type of sampling in which, "particular settings, persons, or events are deliberately selected for the important information they can provide that cannot be gotten as well from other choices". The sample population limits its scope to the students of level one from English Department, Faculty of Arts at IBB University, Yemen for three reasons. First, the policy of the Faculty of Arts and English department presents the reading subject is only for the students of level one. Secondly, the negligence of teaching reading skills from the class 7 to the class 12 resulted from the inappropriate designing of the curriculum that is grammar-based. Another reason for selecting this group is because they were allowed join both traditional learning and web-based learning class. Twenty students were selected to answer the pre-test and post-test questionnaire of reading attitude. The purpose of choosing these twenty participants was to three reasons. First, the computer lab has only twenty workstations. Secondly, many students in Yemen could not afford to use computers as most of them were computer illiterates. Finally, there were not enough PCs in the lab, and therefore, the researcher borrowed some computers from outside the class. Therefore, the students who have had experiences in using the software in a correct way were selected to join the class of reading via computer and answer the pre-test and post-test questionnaire of reading attitude. Additionally, this study carried out a semi-structured interview, involving five students. According to Creswell (2002), a smaller number of respondents between 3 to 5 is adequate for the interview as it reaches the saturation point (saturation point means that until the students' answers become the same thing). The participants who were selected to be interviewed were chosen from the participants who joined the class of web-based reading. Therefore, the process of selecting these interviewees was according to not only their active participation in the reading activities but also to their high abilities to give the researcher clear answers for the given questions.

\subsection{Instruments}

This study used instruments such as questionnaires, interview questions, and observation checklists to achieve the objective of this research. Regarding the questionnaire, pre-test and post- reading attitude questionnaires were distributed among the participants before and after they joined the class of reading via CAREY program. These instruments were adapted from a previous study conducted by Mohaida (2006), who showed the evidence of the reliability and validity of each measurement.

\subsection{Data Collection Procedures}

Before carrying out this study, 20 participants joining the first level in English were selected. Then, the researcher distributed the pre-reading attitude questionnaire to them before they joined the class of reading via CAREY program. During their engagement on the class of reading via CAREY program, the researcher took observations (observations were carried out for eight classes in eight weeks) on their participation until the end of the experiment. At the end of the experiment, the researcher distributed the questionnaire of reading attitude to them, and five participants of them were interviewed. This aimed to provide more information regarding the participants' attitudes towards reading skill in English with technology.

\subsection{Data Analysis}

This study used SPSS program (version, 21) to analyze the data collected from the set of questionnaires during a period of ten weeks. It used the "descriptive statistics" (Percentage, and Frequency) and "compare Means" (t-test) to examine the extent to which the CAREY (Computer-Assisted Reading Yemen) program affects the students' reading attitude towards reading English materials. In brief, this study used the descriptive statistics to determine the three open-ended questions, whereas, it used the "compare Means" to determine the t-test of the participants' attitudes towards reading before and after using CAREY program. However, the participants' responses to the interview questions were analyzed qualitatively that allowed the emergence of several themes; these themes were organized well under the main theme of the research question, whereas, the observations were used as an evidence to crosscheck the interview responses. 


\section{Results}

In this section, the analysis of data collected through a period of ten weeks is presented below.

Table 1 . The results of the participants' attitudes towards CAREY program

\begin{tabular}{lllll}
\hline Statement & \multicolumn{2}{c}{ Yes } & \multicolumn{2}{c}{ No } \\
\cline { 2 - 5 } & Frequency & Percent & Frequency & Percent \\
\cline { 2 - 5 } My reading skills have been improved because of CAREY & 20 & $100 \%$ & 0 & 0 \\
$\begin{array}{l}\text { I believe CAREY program has some positive effects on my } \\
\text { reading attitude }\end{array}$ & 20 & $100 \%$ & 0 & 0 \\
Would you recommend CAREY program to your friends? & 20 & & & 0 \\
\hline
\end{tabular}

Referring to the Table 1, it was noticed that all (20) respondents recommended CAREY program to their friends as a new method to improve the reading skills. In addition, all (20) respondents stated that their skills have been improved because of CAREY program. Furthermore, all (20) respondents believed that CAREY program has some positive effects on their reading attitude.

Table 2. The results of the participants' attitudes before and after using CAREY program (Paired Samples Statistics- Paired Samples Test)

\begin{tabular}{lllllll}
\hline & & Mean & Std. Deviation & T & Df & Sig. (2- tailed) \\
\hline Pair1 & Before & 69.2000 & 13.18133 & -9.254 & 19 & .000 \\
& After & 102.4500 & 14.06554 & & & \\
\hline
\end{tabular}

Referring to Table 2, as shown above, the M and SD of all participants before they joined the class of reading via computer (CAREY program) were $(M=69.2000, S D=13.18133)$, whereas the $\mathrm{M}$ and SD of all participants after they joined the class of reading via computer (CAREY program) were $(M=102.4500, S D=14.06554)$. The Paired Sample T-test shows that there is a significant difference (.000) between the pre- and post-test on their attitude towards English materials via CAREY program at alpha level $p<0.5$. In other words, it indicates that students show positive atitudes in using CAREY program.

\section{Discussion}

Based on the results mentioned in Table 1, the findings showed that all the participants exhibited positive attitudes toward reading English materials via CAREY program. Therefore, they emphasized that their reading skills improved because of their reading through the CAREY program. The CAREY program pushed up the participants from the negative side to the positive side towards reading English materials. Chiu (2013) pointed out that computer-assisted instruction has a positive effect on students' attitudes towards learning L2 vocabulary. In addition, Cheung and Slavin (2011) stated that the positive effects are produced through the use of educational technology applications comparing to the traditional method. The innovation of technology applications and integration of literacy interventions with supplement of intensive progress provided more promising evidence of the effectiveness of educational technology application on the reading outcomes of K-12 classrooms. Bhooth et al. (2014) stated that the social and technological changes in the environment do affect the process of learning which in turn demands changes in education. It was also found that all the participants believed that CAREY program had its positive effect on their reading attitudes. They stated that they changed their view of the teacher as the only source of guidance for them inside the classroom. Moreover, the desire of all participants to recommend the CAREY program to others is a clear evidence of the positive effect of such program in the process of enhancing and improving the reading skills. The findings are similar to those reported by Tseng (2007) and Sung et al. (2008) who stated that technology can help students to improve their reading comprehension if the programs are designed appropriately. In addition, Chem and Lin (2009) and Abanomey (2013) revealed that online reading is beneficial for the students to improve their reading performance.

According to the results mentioned in Table 2, it was found that all participants showed positive attitudes toward 
reading English materials. Their positive attitudes were identified after they had experienced reading through the CAREY program. In addition, there were positive changes toward reading after using the CAREY program. The significant difference in the t-test shows a clear evidence of the positive changes in the participants' attitudes toward reading English materials after using CAREY program. In brief, the Mean of the participants' score before they joined the class of reading via CAREY program was (69), and it increased to (102) after they joined. Hence, the difference of 33 is significant, as illustrated in the paired t-test, indicating that the learners showed positive attitudes towards reading. To conclude, the CAREY program has positively affected the participants' attitudes towards reading English materials. The positive attitudes of the participants toward reading resulted from the application of the new approach to teaching reading skills using CAREY program. As stated by Nasr (2011:25), "the methods used for teaching reading skills in the Yemen schools so far are inappropriate and the teachers use the old method instead of using the appropriate technology and techniques of teaching reading". Zhao and Zhu (2012) also argued that the conventional method failed to improve and develop students' reading skills and increase their reading speed. The conventional teaching method is teacher-centered, which leads students to become passive learners in the whole teaching process. Similarly, Hong (1997) illustrated that the use of multimedia computer-assisted reading is more effective in the efficiency of students' reading and reading comprehension than the conventional method. The findings are compatible with past studies like Akbulut (2007), who pointed out that reading through hypermedia does affect the participants positively particularly their attitudes towards the reading foreign languages and learning vocabulary. Moreover, Busch (2003) stated that the on-line materials and web-based application played a vital role in language learning through buying some more time and to convert certain in class activities.

As noticed from the interviewees' responses, it was found that the majority of the participants showed positive attitudes toward the effectiveness of CAREY program in reading English materials. In brief, they majority of them emphasized that the CAREY program guided them to enhance the reading skills, and some of them stated that CAREY program guided them to be independent learners while others emphasized that they gained the confidence and the motivation after they joined the class of reading via CAREY program. For example, one of the interviewees stated that "I have gained the confidence and the motivation because I am alone and free, there is no one says to me this is true and this wrong and if I don't get the correct answer, the CAREY program will help me to try again and again and this thing make me feel more independent learners. There is no loosing face and you can break the doors and walls, this program help me and I feel like I am independent reader. No one will laugh at me, CAREY program really gives me the motivation to learn more and more because there is no restriction and limitation". Hence, such findings seem similar to the ides of other researchers (David, 2004; Tanyeli, 2009; Biancarosa \& Griffiths, 2012) who emphasized that the traditional materials presented on the form of printed textbooks will not guide and support the students to be independent students. In contrast, they stated that the constant emergency and development of the modern technology has played a vital role in altering the traditional materials. In brief, the interviewees showed positives responses toward the effect of the CAREY program on students' reading attitude towards reading English materials. In addition, all interviewees pointed out that CAREY program affected them positively. Some of them stated that the CAREY program is great because the materials designed in it are related to their culture and their society, whereas others stated that the familiarity of the topics which designed based on their culture guided them for better reading.

In general, learners tend to depend on traditional materials (e.g. hand-outs) prescribed by university instructors for reading skill (David 2004; Tanyeli 2009; Biancarosa \& Griffiths, 2012; Muthanna \& Karaman 2011; Al-Sohbani \& Muthanna 2013). However, appropriate reading materials for these university students are unavailable online. There is a need to create specific reading package that will provide training to read, learning to read, and reading to learn for Ibb university students in Yemen. In line with this, the Internet is presented as a powerful tool for enhancing EFL learners' language learning including reading (Konishe 2003; Balajthy 2007; Simsek 2008; Cheung \& Slavin 2011; Al-Shawesh 2012; Abanomey 2013; Moqbel\& Rao 2013; Han \& Wang 2013) through authentic materials. Thus, reading becomes the most effective skill in this case, and the learners must be highly trained to get used to the techniques of reading especially through the Internet". This is also supported by Park and Km (2011:2161) who stated that "participants considered videos and pictures important resources in online reading environments, and they regarded the resources as helpful for reading English text and studying English". Brandl (2002) stated that it is no doubt that the authentic materials on the Internet provide the learners an opportunity to engage themselves to a real environment of reading.

To support the above discussion, it was randomly observed that all the participants showed positive attitudes toward reading English materials. Their positive attitudes were increased gradually from the beginning of the experiment until the end. The positive changes among the participant's attitudes toward reading English materials 
resulted due to their attendance to the class of reading via CAREY program on time from the induction week to week nine. However, the class of reading via CAREY program is full of all participants from the beginning of the experiment until the end. Furthermore, it was observed by the researcher that some of the participants avoided to ask the teacher for some help; this is evident when they worked on the reading exercises without asking teacher for help towards the end of the experiment as they became familiar with the CAREY features. These features were presented as immediate feedback, online dictionaries, hints, and clues. These features played a vital role in decreasing the role of the teacher inside the classroom. Thus, the participants looked like independence learners; this means that they can do their exercises by their own and without the help of the teacher especially from week three to week eight. Moreover, it was observed that a few of the participants in the second week avoided surfing their Facebook and emails. On the contrary, most of the participants clicked on the icon of enrichment reading materials to further their reading. Also, it was observed that the familiarity of the topics are based on the Yemeni culture and values attracted the participants to engage in further reading. As a result, the researcher was asked by the participants to integrate the CAREY program as a main part of the reading course, and at the same time, they recommended this program to their friends from the same department and advised them to visit the website of that program. Therefore, the findings in this study are compatible to the findings reported by LeLoup and Ponterio (2005) who stated that the ability to access to several authentic reading materials online is a great chance for the learners who would like to practice their language skills in the real world. They also pointed out that the independent reading online is presented as a good way to guide, encourage, and motivate the learners to engage themselves in a real environment of learning reading. Moreover, Abanomey (2013:1) "indicate that the Internet has a positive impact on the overall reading comprehension ability". Similarly, Stakhnevich (2002) stated that the medium of web has an impact on the process of reading comprehension. Therefore, it was suggested that the teaching of reading through web medium will achieve better in the process of comprehension than the traditional medium. Furthermore, Biancarosa, and Griffiths (2012) stated that the development of modern technology nowadays gave the desire and hopes for many teachers, policy makers, administrators who trust with the great help of the modern technology. Thus, what David (2004), Tanyeli (2009), and Biancarosa and Griffiths (2012) argued was precise when they stated that the modern technology played an important role in guiding the students to be independents in the ir learning instead of learning through the traditional materials.

\section{Conclusion}

The current study examined the extent to which the CAREY program affects the EFL Yemeni students' reading attitude towards reading English materials. It was found that CAREY program positively affected the attitudes of the participants toward reading English materials. In addition, it was found that the score of the participants' attitude towards reading English materials using this program positively increased from 69 to 102 after they joined the class of reading via computer. For future studies, it is suggested that more studies should look into the same direction of the current study but with designing other programs in order to see which interesting program that can be used to guide students to read English materials.

\section{References}

Abanomey, A. A. (2013). Do EFL saudi learners perform differently with online reading? an exploratory study. Journal of King Saud University-Languages and Translation, 25, 1-11. http://dx.doi.org/10.1016/j.jksult.2012.12.001

Akbulut, Y. (2007). Effects of multimedia annotations on incidental vocabulary learning and reading comprehension of advanced learners of English as a foreign language. Instr Sci, 35, 499-517. http://dx.doi.org/10.1007/s11251-007-9016-7

Al-Sohbani, Y., \& Muthanna, A. (2013). Challenges of Arabic-English Translation: The Need for Re-Systematic Curriculum and Methodology Reforms in Yemen. Academic Research International, 4,4,

Ashcroft, K., \& Palacio, D. (1996). Researching into Assessment and Evaluation in Colleges and Universities. In K. Ashcroft (Ed.), The Practical research series (pp. 44-61). Great Britain: Biddles Ltd, Guilford and King's Lynn.

Al-Shawesh, M. Y. (2012). The use and perception on online chat rooms for English language learning among the students of Ibb University in Yemen (Unpublished master's thesis). UniversitiKebangsaan Malaysia.

Balajthy, E. (2007). Technology and current reading/literacy assessment strategies. The Reading Teacher, 61(3), 240-247. http://dx.doi.org/10.1598/RT.61.3.4

Balfakeh, S. A. D. (2009). Problems in reading comprehension skills among secondary school students in yemen. Language in India, 9(10). 
Balfakeh, S. A. D. (2011). A Study of reading skills and procedures used by FL university teachers for teaching reading courses to Yemeni undergraduate students (Unpublished doctoral dissertation).University Sains Malaysia.

Bhooth, A. M., Hazita, A., \& Kemboja, I. (2014). Investigating the Reading Practices of EFL Yemeni Students Using the Learning by Design Framework. TESOL Journal, 6(3), 418-446.

Biancarosa, G., \& Griffiths, G. G. (2012).Technology tools to support reading in the digital age. Future of Children, 22(2), 139-160. http://dx.doi.org/10.1353/foc.2012.0014

Brandl, K. (2002). Integrating Internet-Based Reading Materials into the Foreign Language curriculum: From Teacher- To Student- Centered Approaches. Language Learning \& Technology, 6(3), 87-107. http://dx.doi.org/10.1002/tesj.148

Busch, H. J. (2003). Computer Based Readers for Intermediate Foreign-Language Students. Educational Media International, 40(3-4), 277-185. http://dx.doi.org/10.1080/0952398032000113194

Cheung, A., \& Slavin, R. E. (2011). The Effectiveness of education technology for enhancing reading achievement: a meta-analysis. from The Center for Research and Reform in Education, Johns Hopkins University Retrieved from http://www. bestevidence. org/reading/tech/tech. html

Chiu, Y. H. (2013). Computer-assisted second language vocabulary instruction: A meta-analysis. British Journal of Educational Technology, 44(2), 52-56. http://dx.doi.org/10.1111/j.1467-8535.2012.01342.x

Creswell, J. W. (2002). Educational research: Planning, conducting, and evaluating quantitative and qualitative approaches to research. Upper Saddle River, NJ: Merrill/Pearson Education.

Daviad, R. (2004). The role of technology in the guided reading classroom apprenticeships in reading and writing. Scholastic beginning literacy system

Grellet, F. (1996). Developing Reading Skills: A Practical Guide to Reading Comprehension Exercises. New York: Cambridge University Press.

Han, Z., \& Wang, W. (2013). Application of multimedia and network english teaching in multiple intelligence development.

Hong, W. (1997). Multimedia Computer-Assisted in Business Chinese. Foreign Language Annals, 30(3), 336-344. http://dx.doi.org/10.1111/j.1944-9720.1997.tb02356.x

Iman, A. M. (2005). Reading comprehension skills among Yemeni students: A case study (Unpublished doctoral dissertation). University of PUNE, India.

Konishe, M. (2003). Electronic reading: emergence in online text. The Reading Matrix, 3(3).

LeLoup, J. W., \& Ponterio, R. (2005). On the Net Vocabulary Support for Independent Online Reading. Language Learning \& Technology, 9(2), 3-7.

Leu, D. J., Kinzer, C. K., Coiro, J. L., \& Cammack, D. W. (2004). Toward a theory of new literacies emerging from the internet and other information and communication technologies. Theoretical Models and Processes of Reading, 5, 1570-1613.

Marzban, A. (2011). Improvement of reading comprehension through computer-assisted language learning in iranian intermediate efl students. Procedia Computer Science, 3, 3-10. http://dx.doi.org/10.1016/j.procs.2010.12.003

Maxwell, J. A. (1998). Designing a qualitative study. Handbook of applied social research methods, (pp. 69-100).

Mohaida, B. M. (2006). Enhancing reading skills among ESL learners using C.A.R.E. program at the international Islamic university Malaysia (Unpublished doctoral dissertation). UniversitiKebangsaan Malaysia.

Morrison, Gary R. 2010. Designing Effective Instruction, 6th Edition. New Jersey: John Wiley \& Sons.

Moqbel, M. S., \& Rao, L. P. (2013). Enhancing EFL teaching and learning through technology. International Journal of Social Science Tomorrow, 2(2).

Muthanna, A. A. N. (2011). Exploring the beliefs of teacher educators, students, and administrators: A case study of the english language teacher education program in Yemen (Unpublishedmaster's Thesis). Middle East Technical University, Turkish.

Muthanna, A., \& Karaman, A. C. (2011). The Need for change in teacher education in yemen: the beliefs of 
prospective language teachers. Procedia-Social and Behavioral Sciences, 12, 224-232. http://dx.doi.org/10.1016/j.sbspro.2011.02.030

Nadzrah, A. B. (2005). Computer for teaching English as a second language (secondary school) in MALAYSIA: A CASE STUDY. (Unpublished doctoral dissertation). UniversitiKebangsaan Malaysia.

Nasr, A. A. (2011). Teaching of English reading skills: A case study with reference to the colleges of education under the University of Aden (Unpublished doctoral Dissertation). University of PUNE, India.

Park, H.-R., \& Kim, D. (2011). Reading-strategy use by english as a second language learners in online reading tasks. Computers \& Education, 57(3), 2156-2166. http://dx.doi.org/10.1016/j.compedu.2011.05.014

Rahman, H. (2007). An evaluation of the teaching of reading skills of English Bangladesh (Unpublished doctoral Dissertation). University of Rajshahi, Bangladesh.

Rajehy, H. A. A. (2004). Using literary texts to develop reading skills (Unpublished master's Thesis). Hodeidah University, Yemen.

Simsek, S. (2008). Students' attitudes towards integration of icts in a reading course: a case in turkey. Computers \& Education, 51(1), 200-211. http://dx.doi.org/10.1016/j.compedu.2007.05.002

Spörer, N., Brunstein, J. C., \& Kieschke, U. (2009). Improving students' reading comprehension skills: effects of strategy instruction and reciprocal teaching. Learning and Instruction, 19(3), 272-286. http://dx.doi.org/10.1016/j.learninstruc.2008.05.003

Sung, Y.-T., Chang, K.-E., \& Huang, J.-S. (2008). Improving children's reading comprehension and use of strategies through computer-based strategy training. Computers in Human Behavior, 24(4), 1552-1571. http://dx.doi.org/10.1016/j.chb.2007.05.009

Tanyeli, N. (2009). The efficiency of online English language instruction on students' reading skills. Procedia-Social and Behavioral Sciences, 1(1), 564-567. http://dx.doi.org/10.1016/j.sbspro.2009.01.102

Tozcu, A. \& Coady, J. (2004). Successful Learning of Frequent Vocabulary through CALL also Benefits Reading Comprehension and Speed. Computer Assisted Language Learning, 17(5), 473-495. http://dx.doi.org/10.1080/0958822042000319674

Tseng, M. (2007). An investigation of EFL learners' online reading skills. Journal of Nanya Institute of Technology, 27, 111-127.

Tseng, M. C. (2010). Factors that influence online reading: an investigation into EFL students' perceptions. Reading, 10(1).

Widdowson, H. G. (1983). Learning purpose and language use. Oxford University Press Oxford.

Willard, F., \& Harley, J. (1986). Emotional Needs Questionnaire.

Zhao, X., \& Zhu, L. (2012). Schema theory and college english reading teaching. English Language Teaching, 5(11), 111. http://dx.doi.org/10.5539/elt.v5n11p111 


\section{APPENDIX 1}

\section{READING ATTITUDE QUESTIONNAIRE (RAQ)}

INSTRUCTION: Please complete the following questionnaire. The purpose of this questionnaire is to find out your attitudes toward reading English materials.

Please tick (/) once in the appropriate box the statement, which is relevant to you.

\begin{tabular}{|c|c|c|c|c|}
\hline & $\begin{array}{l}\text { Strongly } \\
\text { Agree } \\
4\end{array}$ & $\begin{array}{l}\text { Agree } \\
3\end{array}$ & $\begin{array}{l}\text { Disagree } \\
2\end{array}$ & $\begin{array}{l}\text { Strongly } \\
\text { Disagree } \\
1\end{array}$ \\
\hline 1. I love reading in English & & & & \\
\hline 2. I have a lot of reading materials in English. & & & & \\
\hline 3. I always find it difficult to read in English & & & & \\
\hline 4. Reading in English has been an easy task for me & & & & \\
\hline 5. When I read a text, I can easily get the main idea. & & & & \\
\hline $\begin{array}{l}\text { 6. I always carry a bilingual dictionary with me when I read } \\
\text { English materials }\end{array}$ & & & & \\
\hline $\begin{array}{l}\text { 7. When I read I look for ideas, messages, or concepts that the } \\
\text { writer tries to convey }\end{array}$ & & & & \\
\hline $\begin{array}{l}\text { 8. I always make use of my existing knowledge to understand } \\
\text { what I read. }\end{array}$ & & & & \\
\hline 9.I think I am not good at reading in English & & & & \\
\hline 10. I am a slow reader & & & & \\
\hline 11. I read groups of words rather than a word at a time. & & & & \\
\hline $\begin{array}{l}\text { 12. I know how to guess the meaning of new words based on } \\
\text { the contexts. }\end{array}$ & & & & \\
\hline 13. I read with undivided attention. & & & & \\
\hline 14. It is difficult to remember what I read. & & & & \\
\hline $\begin{array}{l}\text { 15. As I am reading a text, I underline important ideas or make } \\
\text { some marks here and there in the text to indicate important } \\
\text { points. }\end{array}$ & & & & \\
\hline 16.I know how to read quickly and accurately for details & & & & \\
\hline 17. I question statements that are illogical or inaccurate & & & & \\
\hline $\begin{array}{l}18 \text { After reading I always make a summary of what I have } \\
\text { read in a note from }\end{array}$ & & & & \\
\hline 19. As I am reading a text, I make some notes at the margin & & & & \\
\hline $\begin{array}{l}\text { 20. I think about the cover, the title, and what I know about } \\
\text { the topic. }\end{array}$ & & & & \\
\hline 21. I make predictions. & & & & \\
\hline 22. I form a picture in my mind from what I am reading. & & & & \\
\hline 23. I imagine myself in the story or time that I am reading. & & & & \\
\hline 24. I predict and adjust my prediction or confirm it. & & & & \\
\hline $\begin{array}{l}\text { 25. I stop and retell to see what I remember (I reread if } \\
\text { necessary). }\end{array}$ & & & & \\
\hline 26. I don't make connections from the text to my own life. & & & & \\
\hline 27. I think about the events, characters, or information. & & & & \\
\hline
\end{tabular}




\begin{tabular}{|l|l|l|l|l|}
\hline 28. I discuss my reactions. & & & & \\
\hline 29. I reread parts that I enjoy. & & & & \\
\hline $\begin{array}{l}\text { 30. I don't ask myself what the story was about or what I have } \\
\text { learned. }\end{array}$ & & & & \\
\hline $\begin{array}{l}\text { 31. I don't make some marks here and there in the text to } \\
\text { indicate important points. }\end{array}$ & & & & \\
\hline
\end{tabular}

\section{2- Open-ended questions}

1- Would you recommend CAREY program to your friends?

2- In general, my reading skills have been improved because of the computer-assisted reading (CAREY) program.

a- Yes, why?

b- No, why?

3- I believe CAREY program has some positive effects on my reading attitude.

a- Yes, why?

b- No, why?

\section{Interview Questions}

1- How do you find the contents of the CAREY program? Why do you think so?

2- To what extent does CAREY program or any one of the web-based program that you tried affect your reading attitude in reading English materials?

3- Do you feel that by learning reading via the computer, you have gained some confidence and motivation in reading English materials? If yes, in what ways have you gained the confidence and motivation?

4- Does learning via the computer allow you to be more independent? How do you feel about learning at your own pace?

5- Can you compare the two different modes of learning reading that you experienced in this class?

6- Would you recommend CAREY program or some of the websites that you visited to your friends?

\section{Interview Transcripts}

RS is an abbreviation of the word "Respondent"

The responses of the interviewees were analyzed qualitatively that allowed the emergence of several themes; these themes were organized well under the main theme of the research question. This question is:

\section{To what extent does the CAREY program affect the students' reading attitude towards reading in English materials?}

RS1: Ok Yah, I think the website or lets say CAREY program it self is good guide to enhance your reading skills especially how to guess the meaning in the content and I think that the one who tries it, he will feel like he changed himself from negative to positive...

RS1: Ok yes, of course I have gained the confidence and the motivation because I am alone and free, there is no one says to me this is true and this wrong...and if I don't get the correct answer, the program will help me to try again and again and this thing make me feel more independent learners.... There is no loosing face and you can break the doors and walls this program help me .... Ok and I feel like I am independent reader No one will laughs at me... CAREY program really gives me the motivation to learn more and more because there is no restriction and limitation.

RS1: ok Yeh, as I said before you will feel more independent because no one supervisors you, you are learning alone by your self. When I was on my own place to try the CAREY program for the first time I feel with 
happiness... I said to my self it is beautiful to learn by your self and to feel independent without any restriction.

RS1: Yes, there are a lot of programs that the others should use to enhance their reading skills... and I want to say for them don't lose the chance to try the CAREY program because it is very excellent, wonderful and it is very well it is very really amazing because I have tried it and it was very beautiful experience for me because you will be in challenge with your self ... you try and recommend such program like... first of all CAREY program is very well program

RS2: am ...In fact when I use CAREY program I feel more confident because CAREY program improve my skills and I found a lot of information that I found it very important

RS2: am ..Yah because when I read from computer I do not feel shy if I make mistakes or I read some words by wrong way..

RS2: I always learn from the computer or most of my time of learning I spend it on the computer so I am not sure about that feeling so I think I become more independent.

RS2: ok you know.....In learning via the computer I feel more comfortable but in earning in class I am not sure but I think I feel shy more than confortable

RS2: No, when I read from the computer I feel interesting more than when I read from the printed text

RS2: Yes I would recommend it to my friends. If I found something good or helpful or interesting I will tell my friends so yes I will

RS3: It is really affect on me in a good way and it also took me to another level you know what I am saying also it took me from the negative part to the positive, and that is the important thing

RS3: ok, of course I gained some confidence and motivation because it is allowed me to read in my own pace without worrying about anything around and that's an important thing

RS3:Yeah as I said before it is allowed me to read in my own pace because I really feel shy when I read in the class but via computer it is really much better

RS3:Ooh , well.. reading via computer is also much better because reading from books is lit bit boring ... you know what I am saying.. And little bit harder but via computer it is very interesting and very useful and I enjoy it very much when I use it

RS3: yeah why not because it is really a great program and they can get a lot of benefits from it and also to improve their skills

RS4: I found it very great and so challenging because topic with from my society and different exercises like capple, reovers, timers, and direct question of the passage... really to challenge and ....

RS4: you know reading via the computer help me more and more it is really affect me, it give me a self confident and you know now I am no that shy again

RS4: yeah, I think I have got more than that I am now reading better than any one in the class else the that CARRY gave to me is bigger than what I said and even the doctor get surprise of my level after I used CAREY program

RS4: oh, I fell that I get power to read via computer at home at any time and whatever topic they can read without get embarrassing in the class the over class look at me, so I get independence in my home read it...

RS4: Surely I will do that..., I will tell my friend if they want to improve your reading they must use CAREY program and such program like it

RS5: am what I am saying is ... in this question, I mean the CAREY program shift our thinking specially my thinking from the negative side to the positive side and I am so happy to use this CAREY program

RS5: of course... as I said before ... CAREY program is giving me the light in my life in the way that I am going with, and motivation and confidence and so on

RS5: yeah. For me... I am independent man ... learning g on my own pace ... sometimes I know how to type or join class... sometimes I am free at night, so I am study at home in my own place that what I want to say

RS5: Absolutely sometimes when I am readingin the book as the same time I listen to music but I mean when use it electronically ... I mean in this CAREY program. You can listening and reading at the same time

RS5: whatever I go to visit my friends I told them to use this CAREY program, it is really nice to guide you to the good way and give you a lot of chance to be self confidence and to give experience to prepare tofel test 


\section{OBSERVATION CHECKLISTS}

\begin{tabular}{|c|c|c|c|c|c|c|c|c|}
\hline $\begin{array}{l}\text { Observations were carried out among the } \\
\text { participants in the } \\
\text { Classroom }\end{array}$ & W1 & $\mathrm{W} 2$ & W3 & W4 & W5 & W6 & W7 & W8 \\
\hline Ask help from teacher & & & & & & & & \\
\hline Ask help from friend & & & & & & & & \\
\hline Chit-chat with friends & & & & & & & & \\
\hline Speak to oneself/ think aloud & & & & & & & & \\
\hline Check dictionaries & & & & & & & & \\
\hline Check grammar/references book & & & & & & & & \\
\hline $\begin{array}{l}\text { Look for clues/hints for answer and } \\
\text { feedback }\end{array}$ & & & & & & & & \\
\hline Click on hypertext/ linked words & & & & & & & & \\
\hline Skip some exercises & & & & & & & & \\
\hline Always give up & & & & & & & & \\
\hline Bring English dictionaries & & & & & & & & \\
\hline $\begin{array}{l}\text { Look for another sites after they complete } \\
\text { the exercises }\end{array}$ & & & & & & & & \\
\hline Come on time & & & & & & & & \\
\hline Come early to check emails & & & & & & & & \\
\hline Visit other links & & & & & & & & \\
\hline $\begin{array}{l}\text { Feel confident while using } \text { CAREY } \\
\text { program }\end{array}$ & & & & & & & & \\
\hline Look to the pictures before the texts & & & & & & & & \\
\hline Move through index & & & & & & & & \\
\hline $\begin{array}{l}\text { Click on the icon of check to check the } \\
\text { correct answer }\end{array}$ & & & & & & & & \\
\hline $\begin{array}{l}\text { Look nervous while reading by CAREY } \\
\text { program }\end{array}$ & & & & & & & & \\
\hline $\begin{array}{l}\text { Look excited while reading by CAREY } \\
\text { program }\end{array}$ & & & & & & & & \\
\hline $\begin{array}{l}\text { Look happy while reading by CAREY } \\
\text { program }\end{array}$ & & & & & & & & \\
\hline $\begin{array}{l}\text { Look afraid and scared while reading by } \\
\text { CAREY program }\end{array}$ & & & & & & & & \\
\hline $\begin{array}{l}\text { Look worry while reading by CAREY } \\
\text { program }\end{array}$ & & & & & & & & \\
\hline $\begin{array}{l}\text { Going through tutorials before dealing with } \\
\text { exercises }\end{array}$ & & & & & & & & \\
\hline Follow the sequences of the program & & & & & & & & \\
\hline Surf internet & & & & & & & & \\
\hline $\begin{array}{l}\text { Listen to the researcher while introducing } \\
\text { CAREY program }\end{array}$ & & & & & & & & \\
\hline Feel comfortable while reading through & & & & & & & & \\
\hline
\end{tabular}




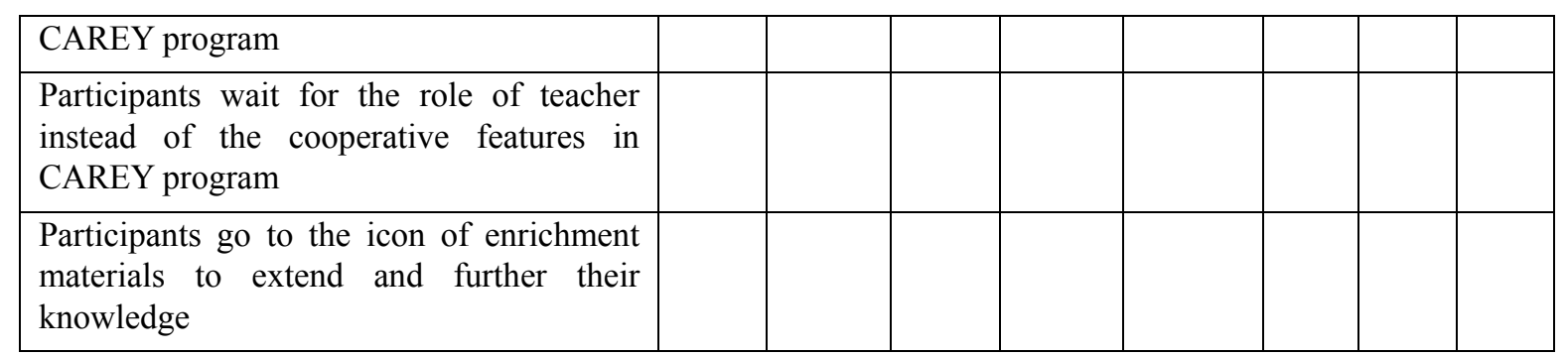

\section{Copyrights}

Copyright for this article is retained by the author(s), with first publication rights granted to the journal.

This is an open-access article distributed under the terms and conditions of the Creative Commons Attribution license (http://creativecommons.org/licenses/by/3.0/). 